\title{
The Design of Electric Conversion and Energy Storage Integration of Sofc Combined Power Supply System Based on Feature Fusion
}

\author{
Shuijin $\mathrm{Lu}^{1}$, and Yujie $\mathrm{Mo}^{1 *}$ \\ ${ }^{1}$ Yangtze Delta Region Institute of Tsinghua University, Jiaxing, Zhejiang, 314006, China
}

\begin{abstract}
In order to reduce the low effective utilization of the combined thermal power supply system caused by the abnormal energy distribution, the design of the electric conversion and energy storage integration of SOFC combined power supply system based on feature fusion is proposed. The design of internal combustion engine, heat storage device and battery is carried out. Based on the system temperature, SOFC heat exchanger model is established. The energy state in the heat exchanger model is analyzed and judged by feature fusion. According to the results, the energy is converted, stored and released. The experimental results show that the energy utilization efficiency of the system can reach $81.57 \%$, which is $36.9 \%$ higher than the source system, which has good application value.
\end{abstract}

\section{Introduction}

At present, the reserves of traditional fossil energy such as coal, oil and natural gas are gradually reduced. In the process of exploiting and utilizing various traditional fossil energy, human beings have caused serious environmental crisis ${ }^{[1]}$, under this background, it is an important measure to find new renewable energy to ensure energy supply and solve environmental crisis. Among the many new energy sources, hydrogen energy is undoubtedly one of the most promising energy sources. Hydrogen energy has many advantages such as wide application, convenient for large-scale storage and transportation, high energy density, clean and pollution free. ${ }^{[2]}$, and is known as "the ultimate energy in the $21 \mathrm{st}$ century". Currently, the commonly used hydrogen preparation method is to use natural gas, oil, coal and other reforming to produce hydrogen, which not only wastes precious non renewable energy, but also faces the problem of secondary pollution, and is not an ideal way to produce hydrogen. The most clean and efficient way to prepare hydrogen is to produce hydrogen by electrolysis reaction of water ${ }^{[3]}$. Based on this, this paper proposes the research on the electrical conversion and energy storage integration design of SOFC combined power supply system based on feature fusion. The practical application performance of the design system is verified by experiments. Through this study, it provides valuable reference for the practical work.

\section{Hardware Design}

\subsection{Internal combustion engine}

As a power device providing electric energy, combustion engine $(\mathrm{CE})$ is generally rated between hundreds and thousands of kilowatts. It converts the heat emitted by the combustion of gas into power directly by burning gas in the interior. The internal combustion engine is a cycle process $^{[4]}$. After gas and air enter the cylinder of internal combustion engine, high temperature and high pressure flue gas are generated through combustion process to push the internal combustion engine to work to generate electric energy, and then the high-temperature gas is used for secondary use. The exhaust gas discharged from the internal combustion engine after working is generally about $400 \mathrm{OC}$, so the residual heat can be further recovered to generate hot water and steam, or the cooling / heat of absorption type chiller can provide the user with cold / heat. Therefore, the internal combustion engine is chosen as the core power unit of the cogeneration system. Compared with gas turbine, internal combustion engine has better partial compliance characteristics, so this paper selects internal combustion engine as the core power generation device of cogeneration system.

\subsection{Heat storage device}

In the actual operation of the cogeneration system, the actual thermal load ratio of the user is not consistent with that of the internal combustion engine. At this time, the introduction of thermal storage (TS) with appropriate 
capacity to adjust the heat load can play a role in peak filling and valley filling and improving economic efficiency ${ }^{[5]}$. When the thermal load ratio of the user is too low (i.e. the power demand of the user is too high and the demand for cold and heat is very small), the internal combustion engine will reduce the power generation due to the low utilization efficiency of the waste heat, which will reduce the thermal power utilization efficiency of the internal combustion engine; When the thermal load ratio of the user is too high (i.e. the user's demand for cold and heat is too high and the power demand is very small), it will cause the internal combustion engine to generate excess power, which may cause the waste of electricity and limit the internal combustion engine can not improve the power generation, thus causing the waste heat shortage to meet the heat demand of the user, which makes the cogeneration system unable to operate efficiently and economically.

\subsection{Battery}

Due to the randomness and volatility of the output of photovoltaic power generation and wind power generation equipment integrated in the cogeneration system, the power storage equipment with appropriate capacity can improve the power supply quality and reliability better. In addition, according to the timesharing price adopted by grid companies, the electric energy storage equipment is used to charge in the valley price period, discharge energy supply in peak area price period or sell surplus power to the grid can obtain good economic benefits ${ }^{[6]}$. At present, battery storage (BS) is the most widely used electrical energy storage equipment. Battery is a device which converts chemical energy directly into electric energy, and recharges by reversible chemical reaction. In this paper, pj2v400 of GNB is chosen as the battery of the design system. The battery cover and exhaust bolt structure are valve controlled sealed structure, belonging to lead-acid battery, with rated capacity of 4000ha and rated voltage of $220 \mathrm{~V}$. Under the humidity of $0-95 \%$, condensation will not occur, which is applicable for the thermal power supply system.

\section{Software design}

\subsection{Build SOFC heat exchanger model}

In order to maintain the operating temperature of SOFC, heat exchanger must be installed for SOFC. In order to isolate the external environment from the internal environment, the fluid conducting heat exchange, namely the circulating water inside and outside, should be insulated by heat conduction during the heat exchange process $^{[7]}$. Because the inlet temperature of heat exchange hot water is $60{ }^{\circ} \mathrm{C}$, it is far less than the boiling point of water, so it can be considered as a heat exchanger without phase change. Therefore, it is obtained that the heat transfer from one fluid through a diaphragm to another depends on the temperature difference and thermal resistance, that is, there are

$$
Q=U A \Delta T_{m}
$$

Where $Q$ is the heat flow rate, $U$ is the heat transfer coefficient of the system, and $A$ is the surface area of the heat exchanger. It can be seen from (1) that the heat flux $Q$ can be controlled by changing the heat transfer coefficient $U$, the surface area $A$ and the average temperature difference between the fluids $\Delta T_{m}$. Temperature control is the goal of SOFC heat exchanger ${ }^{[8]}$. The temperature changes with the change of soft heat rate, but it affects the heat transfer in turn like equation (1). Therefore, most heat transfer engineering has a high degree of self balancing ability.

$$
\Delta T_{m}=\frac{\left(T_{H 1}-T_{H 2}\right)-\left(T_{C 1}-T_{C 2}\right)}{\ln \left[\left(T_{H 1}-T_{H 2}\right) /\left(T_{C 1}-T_{C 2}\right)\right]}
$$

Among them, $T_{H 1}$ and $T_{H 2}$ represent the water temperature at the inlet and outlet of internal circulation respectively, $T_{C 1}$ and $T_{C 2}$ represent the water temperature at the inlet and outlet of external circulation respectively.

Then the SOFC heat exchanger model can be expressed as

$$
T_{m}=\frac{\lambda \Delta T_{m}}{\left(T_{H 1}-T_{H 2}\right)-\left(T_{C 1}-T_{C 2}\right)}
$$

Where $T_{m}$ is the total available temperature generated by the system, and $\lambda$ is the availability factor.

\subsection{Thermal state analysis based on Feature Fusion}

The electrical conversion of thermoelectric training system is formed by the combination of various components of the system, and then by the logical relationship between the import and export parameters of each component. In this paper, we use feature fusion to judge its state. The process is shown in figure 1 .

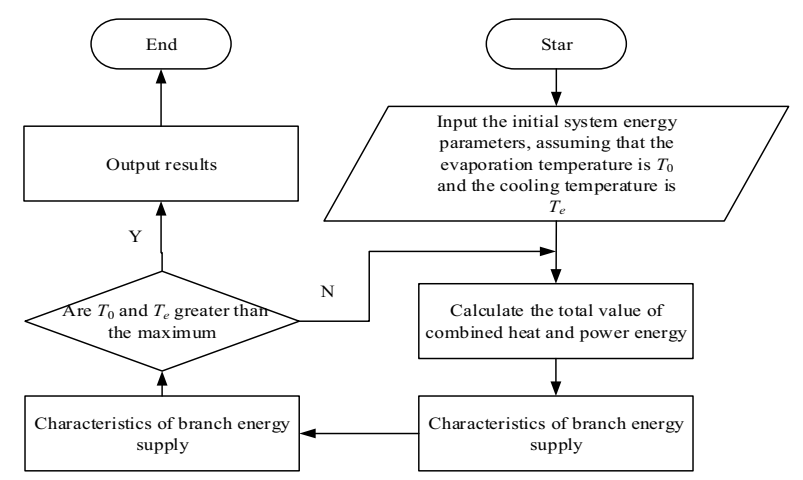

Fig.1 Thermal state analysis process based on Feature Fusion

It can be seen from figure 1 that the circulating evaporation temperature is equal to the water supply temperature of the heat storage tank minus the heat exchange temperature difference of the evaporator, 
which depends on the heat exchange area of the evaporator.

\subsection{Energy state transition}

In this system, the internal circulating water represents the load of the heat exchanger, and the outlet temperature of the internal circulating water is controlled by the opening and closing of the external circulating water. The temperature transformation of the two kinds of fluids affects each other, namely

$$
Q=W_{1} * C\left(T_{H 1}-T_{H 2}\right)=W_{2} * C\left(T_{C 1}-T_{C 2}\right)
$$

Using $Q /\left(W_{1} * C\right)$ and $Q /\left(W_{2} * C\right)$ instead of the temperature difference in equation (2), the relationship between the outlet temperature of internal circulating water and that of external circulating water can be obtained

$$
T_{H 2}=T_{C 1}+\varepsilon\left(T_{H 1}-T_{C 2}\right)
$$

Among them, $\varepsilon$ is the coefficient of temperature difference

$$
\varepsilon=e^{U A / *(W 2 * C)-U A /\left(W 1^{*} C\right)}
$$

Where $R=W_{1} / W_{2}$. For any group of flow rate and inlet temperature, the normalized value of $T_{H 2}$ can be obtained according to equation (4).

$$
\frac{T_{H 1}-T_{H 2}}{T_{H 1}-T_{C 1}}=\frac{1-\varepsilon}{1-R \varepsilon}(R \neq 1)
$$

When $R=1$, obviously $\varepsilon=1$. The solution of the above formula does not exist, but the function is continuous, and according to the two sides of the point. It is easy to determine the value of the point, so that the simple number solution of the point can be obtained as follows:

$$
\frac{T_{H 1}-T_{H 2}}{T_{H 1}-T_{C 1}}=\frac{1}{W^{*} C / U A+1}\left(W=W_{1}=W_{2}\right)
$$

It can be seen from (8) and (9) that the outlet temperature of the internal circulating water is closely related to the inlet temperature of the internal circulating water, that is, the inlet temperature of the external circulating cooling water. Since the flow rate of the internal and external circulating pumps in our system is customized, it can be considered that the heat transfer rate $\mathrm{u}$ is a constant. Similarly, it can be deduced that $A$, $W_{1}, W_{2}$ and $C$ are constants, that is, the right side of equation (8) is a constant, and it can be concluded that the temperature drop of the internal circulating water is directly proportional to the inlet temperature of the internal and external circulating water. In this way, the energy of SOFC cogeneration system can be effectively utilized.

\section{Experiment and analysis}

\subsection{Test environment}

The test platform is mainly composed of power generation system and heat exchange system. The power generation system mainly includes power stack, hydrogen supply system, air supply system, hydrothermal management system and control system. All components cooperate with each other to ensure the normal operation of the power generation system. The control system can ensure the normal and stable operation of the system according to the sensor signal and the given control strategy.

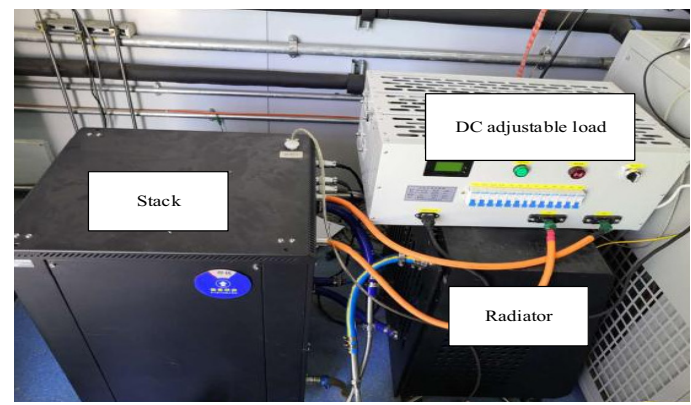

Fig.2 Test platform

In the test platform of SOFC power generation system, DC adjustable load is used to simulate the change of real load. When the load changes, the output current, voltage, power and other parameters of the stack also change, so as to study the output characteristics of SOFC power generation system. The test platform shown in figure 3 above uses radiator to control the temperature of the stack. The heat generated during the operation of the stack is directly discharged into the surrounding environment, resulting in a huge waste of energy. It is necessary to add another heat exchange system to realize the cogeneration of SOFC.

\subsection{Test parameters}

SOFC system operation adopts remote control. SOFC system uses can $2.0 \mathrm{~B}$ interface to communicate with upper computer to realize the control of equipment by operators. The control commands of the upper computer to the system include: 1 - start up; 2 - standby; 3 shutdown; 4 - emergency stop; 5 - purge; 6 - output

\begin{tabular}{|c|c|c|c|c|c|}
\hline Parameter name & Index & Remarks & Parameter name & Index & Remarks \\
\hline Rated power & $5 \mathrm{~kW}$ & Net output power & Peak power & $5.5 \mathrm{~kW}$ & Net output power \\
\hline $\begin{array}{l}\text { Open circuit } \\
\text { voltage }\end{array}$ & $60 \mathrm{~V}$ & $\begin{array}{l}\text { Maximum output } \\
\text { voltage of stack }\end{array}$ & Number of cells & 60 & - \\
\hline $\begin{array}{l}\text { Peak power } \\
\text { duration }\end{array}$ & $10 \mathrm{~min}$ & $\begin{array}{l}\text { The operating time can } \\
\text { be extended properly } \\
\text { when the ambient } \\
\text { temperature is reduced }\end{array}$ & Rated efficiency & $45.9 \%$ & $\begin{array}{l}\text { Excluding power } \\
\text { electronic converter } \\
\text { efficiency }\end{array}$ \\
\hline
\end{tabular}
power setting. The technical parameters of proton exchange membrane SOFC power supply system are shown in table 1 .

Tab.1 Test parameters 


\subsection{Analysis of test results}

By running the test platform and recording and sorting the relevant test data, the performance parameters of the test platform are obtained. The test results are as follows.

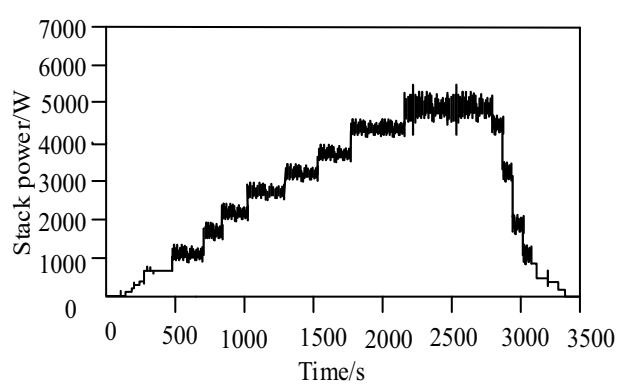

Fig.3 Power curve of stack during test

The power of the stack can be set independently by remote operation. Figure 3 shows the change of the power of the stack during the test. By sending load and unload power commands to SOFC stack, the stack power can quickly track the change of command value, and the whole system has good dynamic response characteristics. During the test, the maximum stack output power can reach about $5 \mathrm{~kW}$, and the stack power meets the design requirements.

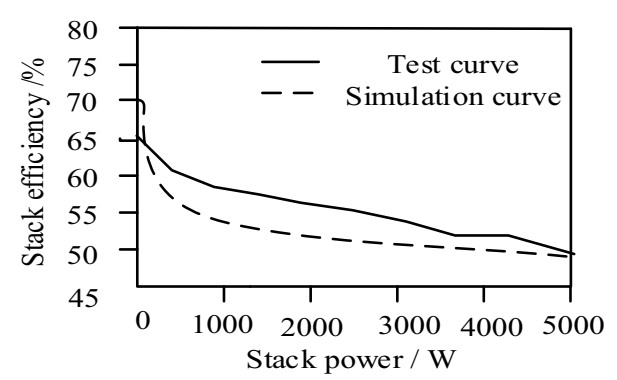

Fig4. Electric efficiency curve of stack

Figure 4 the electric efficiency curve of the stack shows the ratio of the output power of the stack to the total energy of the hydrogen participating in the reaction. Part of the chemical energy contained in the hydrogen participating in the reaction is converted into electric energy, and the other part is dissipated in the form of heat energy due to the polarization loss during the reaction. As the proportion of polarization loss increases with the increase of stack power, the stack efficiency decreases gradually with the increase of stack output power. When the stack operates at $5 \mathrm{~kW}$ rated power, the stack efficiency of the test platform is about $49.7 \%$.

\section{Conclusion}

Fuel cell is a kind of clean energy with high efficiency, low noise and low pollution. Proton exchange membrane fuel cell (PEMFC) has been paid more and more attention in the past few decades due to its outstanding characteristics of rapid start-up at room temperature, convenient drainage, low pollution, long service life and high specific power and energy, It can be expected that for a long time in the future, proton exchange membrane fuel cell will still be the focus of energy research. But fuel cells are still a long way from commercialization. In the process of developing proton exchange membrane fuel cell into fuel cell power supply to the outside world, many technical problems still need to be solved in order to make fuel cell become a real power supply.

\section{Acknowledgement}

The study was supported by "Department of Science and Technology of Zhejiang Province, China (Grant No. 2019C01149)".

\section{References}

1. Corigliano O, Lorenzo G D, Fragiacomo P. Preliminary design of AR/SOFC cogeneration energy system using livestock waste[J]. Procedia Computer Science, 2021, 180(1):935-942.

2. Shunya, SUMITOMO, Atsushi, et al. Installation Effects of Solid Oxide Fuel Cell Cogeneration for Commercial Buildings[J]. Journal of the Japan Institute of Energy, 2019, 98(7):149-156.

3. Hassan S Z, Li H, Kamal T, et al. Load Sharing and Arrangement through an Effective Utilization of SOFC/Super-capacitor/Battery in a Hybrid Power System[J]. Iranian Journal of Science and Technology, Transactions of Electrical Engineering, 2019, 43(2):383-396.

4. R Dückershoff, Berg H P, Himmelberg A, et al. Influence on the Electrical Efficiency of a Hybrid MGT-SOFC-System by $\mu$-fogging in a-TwoStaged Compressor System[J]. IOP Conference Series: Materials Science and Engineering, 2020, 886(1):012041 (8pp).

5. Gandiglio M, Sario F D, Lanzini A, et al. Life Cycle Assessment of a Biogas-Fed Solid Oxide Fuel Cell (SOFC) Integrated in a Wastewater Treatment Plant[J]. Energies, 2019, 12(9): 1-31.

6. Aguemon D P, Gilles R, Dubas F, et al. A Comprehensive Analysis and Review on Electrical Machines in Wind Energy Conversion Systems[J]. Advanced Engineering Forum, 2020, 35:77-93.

7. Jia K, Zhao Q, Feng T, et al. Distance Protection Scheme for DC Distribution Systems Based on the High-Frequency Characteristics of Faults[J]. IEEE Transactions on Power Delivery, 2020, 35(1):234243.

8. Wu Hongbin, Wang Dongxu, Liu Xingyue. Strategic evaluation and optimization configuration of solar energy cold and thermal power combined supply system [j]. Power system automation, 2015 (21): 46-51. 